\title{
TOPOFIRE
}

\section{A Topographically Resolved Wildfire Danger and Drought Monitoring System for the Conterminous United States}

\author{
Zachary A. Holden, W. Matt Jolly, Alan Swanson, Dyer A. Warren, Kelsey Jencso, \\ Marco Maneta, Mitchell Burgard, Chris Gibson, Zachary Hoylman, and Erin L. Landguth
}

D rought can directly impact ecosystem function through reductions in productivity, but it can also indirectly impact people and ecosystems via disturbances such as wildfires. While often considered separately in terms of impacts, drought and wildfires are fundamentally linked by the weather conditions that drive moisture deficits in woody fuels and soil, which both increase potential for wildfire activity, as well as increase demand for water resources. Drought and wildfire danger are monitored at local, regional, and national scales, and the assessments made by various monitoring efforts impact a range of decisions including disbursement of drought mitigation funding, surface water allocation, and strategic placement of wildland firefighting resources.

The last decade has seen a proliferation of drought and wildfire danger monitoring systems. However, the primary source of drought condition information in the United States is the U.S. Drought Monitor (USDM; Svoboda et al. 2002). The USDM assessments integrate

AFFILIATIONS: HOLDEN-U.S. Forest Service Region I, Missoula, Montana; Jolly AND BURGARD-U.S. Forest Service Rocky Mountain Research Station, Missoula, Montana; SWANSON, WarRen, AND LANDGUtH-School of Public and Community Health Sciences, University of Montana, Missoula, Montana; Jencso AND HoYlman-University of Montana College of Forestry and Conservation, Missoula, Montana; MANETA-University of Montana Department of Geosciences, University of Montana, Missoula, Montana; Gibson-National Weather Service Forecast Office, Missoula, Montana

CORRESPONDING AUTHOR: Zachary A. Holden, zaholden@fs.fed.us

DOI:10.II75/BAMS-D-18-0178.I

(C)2019 American Meteorological Society

For information regarding reuse of this content and general

copyright information, consult the AMS Copyright Policy. numerous sources of information, including gridded weather data, satellite information, stream gauge and reservoir data, and local reporting from state drought task forces to provide weekly assessments of drought status across the United States. Outputs from the USDM are widely used for reporting and summarizing drought conditions. One strength of the USDM is that expert opinion and on-the-ground reporting are used to supplement model inputs, which are integrated into weekly maps. However, the USDM does not attempt to resolve topographic variations in soil moisture availability or drought, and users are cautioned against using USDM maps for local decisionmaking. The drought indices that are combined for USDM mapping purposes are located across many data providers and are released at different resolutions and time frames, which can make summarizing local conditions challenging.

In mountainous regions, patterns of energy and available moisture can vary substantially over small $(<1 \mathrm{~km})$ distances. Increased precipitation and decreased temperature with elevation, coupled with differences in incident shortwave radiation with aspect position, result in finescale variations in surface air temperature, humidity, snowmelt timing, and soil moisture. At night, cold air drains into mountain valleys and under certain atmospheric conditions creates temperature inversions that lead to cold air pools and bands of warmer air, or thermal belts above them (Geiger et al. 1995; Whiteman, 2000). Furthermore, surface temperatures vary dynamically in time and space; the magnitude of cold air drainage depends on both landscape position and regional atmospheric patterns, and variations in daytime temperature vary as a function of the interaction between surface moisture and incident radiation (Holden et al. 2016). In very rugged terrain, these topographic effects are fine-grained and are not fully resolved by the gridded 
datasets that are widely used for assessing drought conditions. Ultimately, there is a need to capture and map finescale weather patterns and to integrate that information into high-resolution drought indices that can be used to inform local drought adaptations and mitigations. If developed, such information could also fill critical needs for other natural hazards.

Although the role of topography is poorly defined in the context of drought, it is a fundamental part of wildland fire management decision support. Introductory classes teach firefighters about the "fire behavior triangle," with vertices composed of fuel, weather, and topography. At the intersection of these components is what we consider microclimate, where local weather, mediated by terrain position and vegetation cover, influences the conditioning of surface fuels and potential for fire growth. Widely used operational fire models like FARSITE (Finney 1998) use a standard lapse rate of $6.0^{\circ} \mathrm{C} \mathrm{km}^{-1}$ and temperature adjustments at 8 aspect classes to estimate elevation and radiation effects on surface heating. These topographic corrections on heating are then applied to short-term fuel moisture conditioning routines prior to simulating fire spread. However, these adjustments to local fuel conditions are only applied for two weeks before ignition, and other important longer-term antecedent conditions affecting fuel states, like timing of snowmelt, variable lapse rates, and cold air pools are ignored. During the course of a fire season, these and other factors can have a profound impact on fuel moisture conditions that likely influence fire behavior and effects.

Analogous to the USDM, the Wildland Fire Assessment System (WFAS) is a nationally mandated system that serves as the primary source of information on wildfire danger conditions in the United States (Burgan et al. 1997). WFAS was originally developed to support the delivery of remotely sensed vegetation stress and fire danger indices from the Advanced Very High Resolution Radiometer (AVHRR), but it has since evolved to include daily estimates of wildfire danger, and has become an integral tool used by fire managers across the United States as well as other state and local entities to assess potential fire conditions. WFAS relies primarily on data from Remote Automated Weather Stations (RAWS), a network of more than 3,000 stations that collect and transmit hourly weather information from which indices in the National Fire Danger Rating System (NFDRS) are then calculated. Information about the presence of snow cover is manually input by local RAWS station managers into the Weather Information Management System (WIMS),
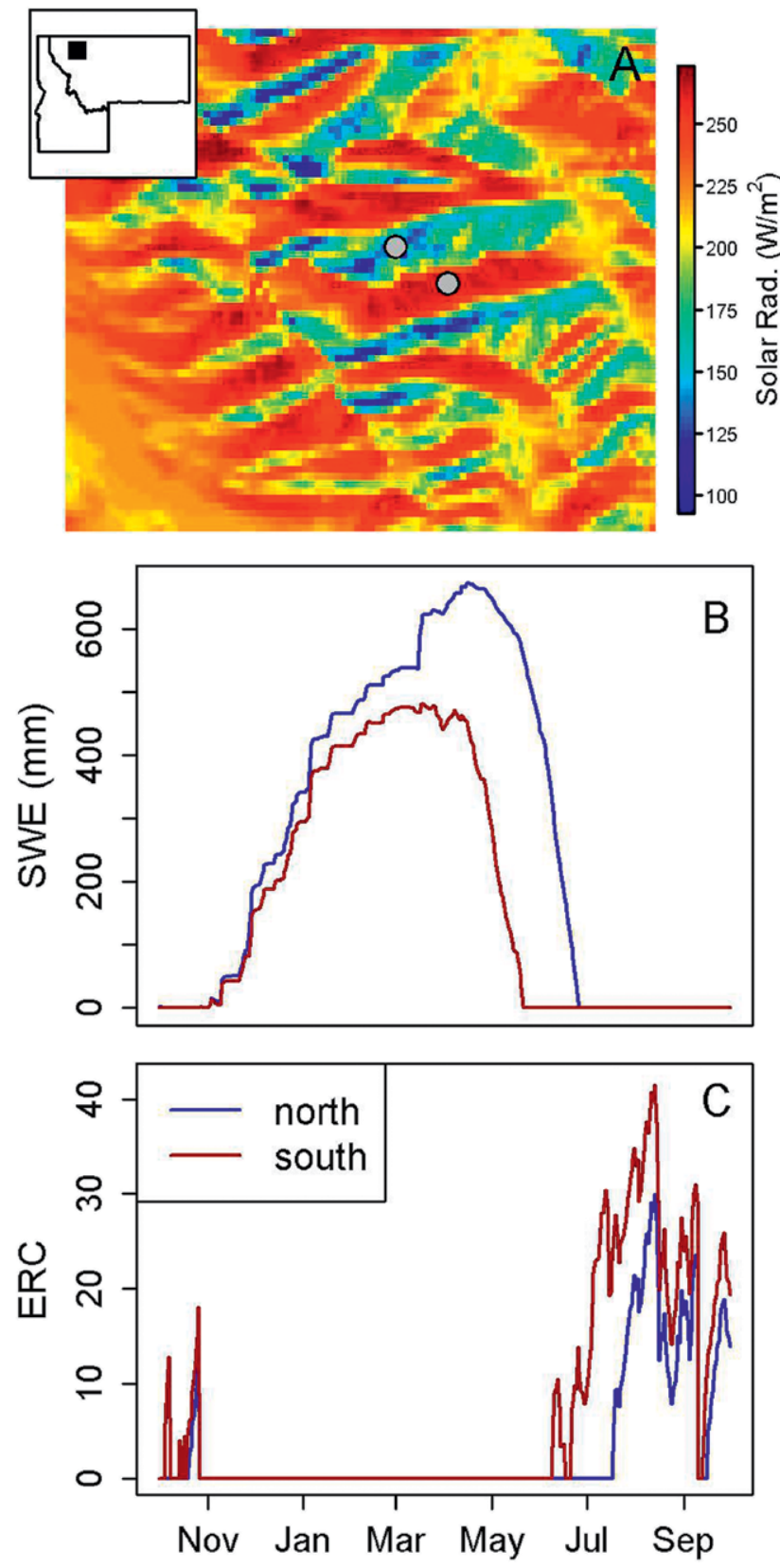

Fig. I. Mean annual solar radiation for the 2014 water year (a) with snow water equivalent (SWE) (b) and Energy Release Component (ERC) traces (c) from TOPOFIRE modeled data at two sites on opposing north- and south-facing slopes at the same elevation. Lower solar radiation results in a significant delay in snowmelt on the north slope site. Cooler temperatures and higher humidity result in persistently higher moisture and lower fire danger throughout the fire season.

which saturates fuel moisture for that station if snow presence is flagged. Daily fuel moisture and NFDRS indices are then interpolated across a 1-km-resolution 


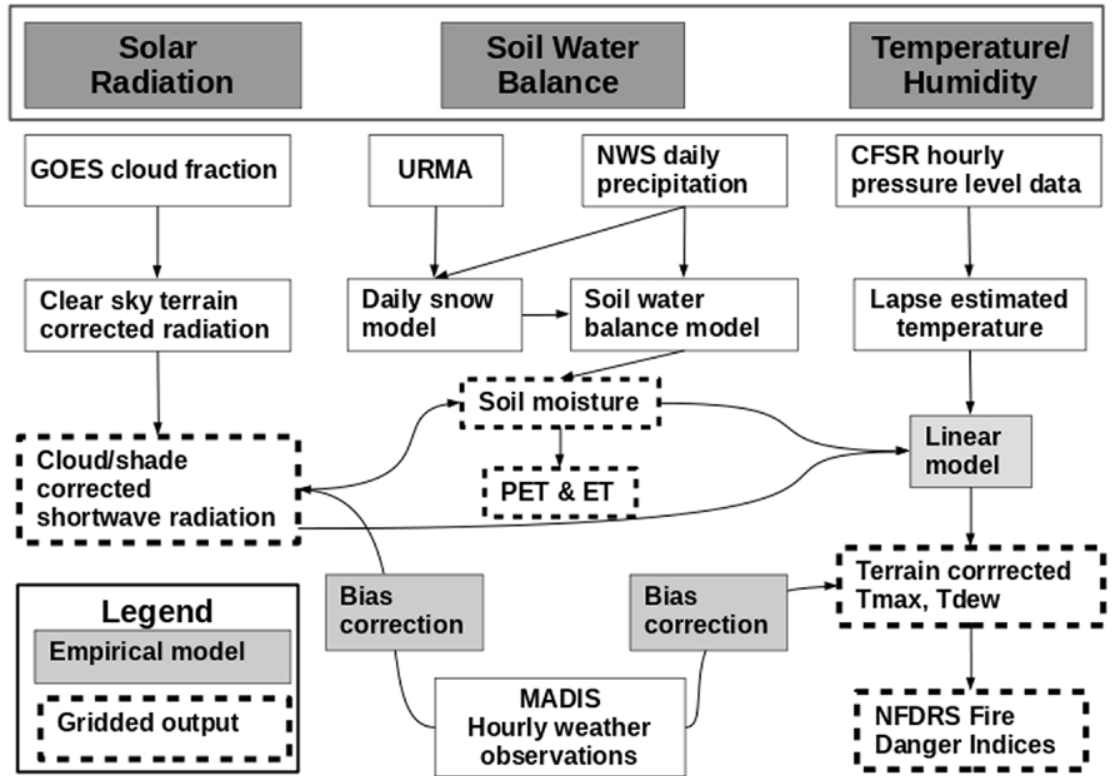

Fig. 2. Overview of the data processing workflow required for producing daily gridded radiation, temperature, humidity, soil moisture, and fire danger grids. CFSR = Climate Forecast System Reanalysis. URMA = Unrestricted Mesoscale Analysis. PET and ET refer to reference evapotranspiration and actual evapotranspiration, respectively. MADIS = Meteorological Assimilation Data Ingest System. NFDRS = National Fire Danger Rating System.

fuel moisture, and fire danger conditions. The high resolution at which TOPOFIRE represents topographic gradients permits it to capture the effect that terrain geometries have on the spatial distribution of energy inputs, which adds critical decisionmaking value. For instance, the combined effects of lower radiation loads and lower temperatures on north slopes result in a delay of as much as four weeks in the timing of snowmelt on north-facing slopes (Holden and Jolly 2011; Fig. 1). This information could substantially improve both strategic and tactical fire management decisions. More broadly, our experience supporting both drought and wildfire danger assessments has shown us that managers spend significant time collecting information and data from across many different online

grid and provided to users in the form of continuous and qualitative (e.g., "low," "moderate," and "high") fire danger ratings. These spatial and temporal fire danger ratings or indices are used throughout the country to make a variety of wildland fire management decisions that aide in both staffing for and responding to wildfires. Ultimately, there is a need for a single system that can provide critical, high-resolution metrics of both fire danger and drought to meet the current and emerging needs of land and emergency managers throughout the United States. TOPOFIRE was designed and built to fill that crucial need.

VERY HIGH RESOLUTION DROUGHT AND WILDFIRE DANGER MONITORING. With support from the National Aeronautics and Space Administration (NASA) and the U.S. Forest Service, our team developed TOPOFIRE (https://topofire .dbs.umt.edu), an operational fuel moisture, wildfire danger, and drought monitoring system for the conterminous United States. The primary goal of developing this system was to enhance the current WFAS and to expand the decision space for strategic and tactical wildland fire decision support by resolving terrain-mediated variations in local soil moisture, sources. A secondary goal was to facilitate management decisions by integrating a range of more widely used drought and fire danger monitoring products into a single system that includes updated satellite data from NASA. Below we provide a brief overview of TOPOFIRE and provide links for accessing further information about the system.

\section{HISTORICAL AND NEAR REAL-TIME GRIDDED} DATA PRODUCTS. Daily 8-arc-second-resolution $(\sim 250 \mathrm{~m})$ temperature, dewpoint temperature, and downward shortwave radiation grids are produced on TOPOFIRE each day for the conterminous United States and used as inputs to snow, fuel moisture, and soil water balance models. Our modeling approach adapts previously described methods for producing historical (1979-2015) datasets (Holden et al. 2018, 2016). A schematic overview of the procedures used to generate gridded weather, drought, and fire danger products is shown in Fig. 2.

Briefly, near real-time (NRT) radiation, temperature, and humidity models integrate Climate Forecast System Reanalysis data (CFSR) and the Unrestricted Mesoscale Analysis data (URMA) with Geostationary Operational Environmental Satellite (GOES) data, 


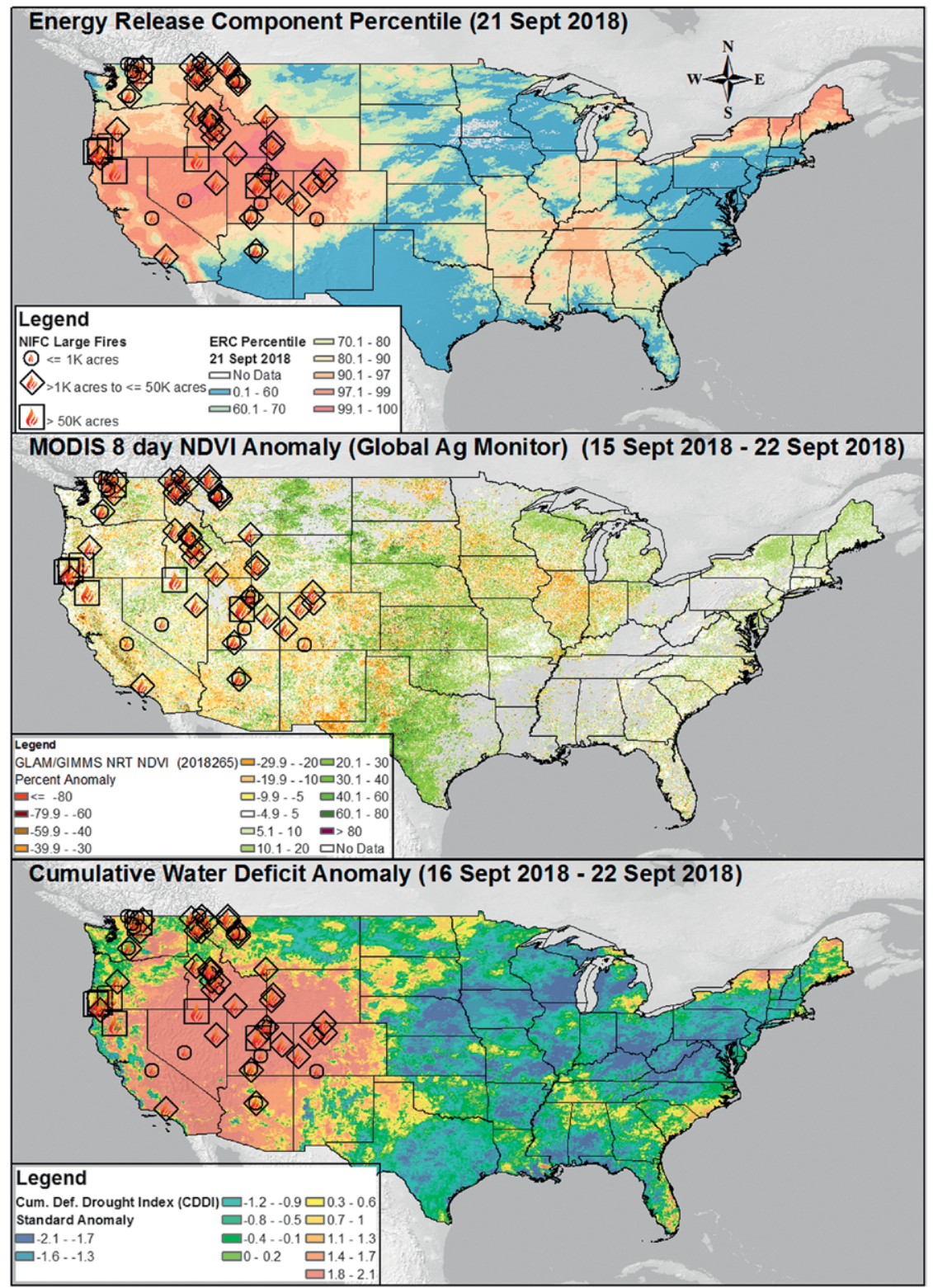

Fig. 3. (top) Example TOPOFIRE Energy Release Component (ERC) percentiles, (middle) MODIS 8-day departure from average greenness, and (bottom) 4-week standardized deficit anomalies for 21 Sep 2018. Large fires ( $>100$ acres) mapped by the National Interagency Fire Center (NIFC) are shown as black squares on each layer. Fire danger percentile and deficit anomaly maps are produced daily as part of the TOPOFIRE processing chain. and humidity grids for the previous day are compared with observations from the Meteorological Data Assimilation System (MADIS), which are ingested into a database of daily observations and used to correct each grid for regional biases. The resulting grids are then used as inputs to the National Fire Danger Rating System (NFDRS), where gridded fuel moisture and fire danger indices are calculated, and the final fire danger grids are normalized based on a 17 -year climatology (2001-17) to produce a daily Energy Release Component (ERC) percentile grid (Fig. 3). Eight arc-second grids are also calculated for four-day forecast periods (current day plus three days ahead) using forecasts from the National Digital Guidance Database (NDGD). Soil water balance grids, which integrate terrain-resolved radiation and temperature data, capture differences in water availability and evaporative demand with aspect position (Fig. 4).

\section{DROUGHT INDICES AND} SUMMARY TOOLS. A suite of widely used drought indices are assembled on the TOPOFIRE server and a list of drought, precipitation, and wildfire danger indices is provided in Table 1. These include the Standardized Precipitation Evaporation Index (SPEI; Vicente-Serrano et al. terrain covariates, and surface weather observations to represent local lapse rates, interactions between radiation and soil moisture, and nocturnal cold air drainage potential. NRT grids are produced for the previous day at approximately 7:00 a.m. local time. These grids are then used to update daily snow water equivalent (SWE) and soil water balance models. Radiation, temperature,
2009) and the Vegetation Drought Response Index (VegDRI; Brown et al. 2008). SPEI data for 1-, 3-, 6-, and 12-month time lags are retrieved from the West Wide Drought Tracker (Abatzoglou et al. 2017), while the VegDRI is updated weekly from the U.S. Geological Survey. The Normalized Differenced Vegetation Index (NDVI) and departure from average 


\section{Climatic Water Deficit, 30yr mean}

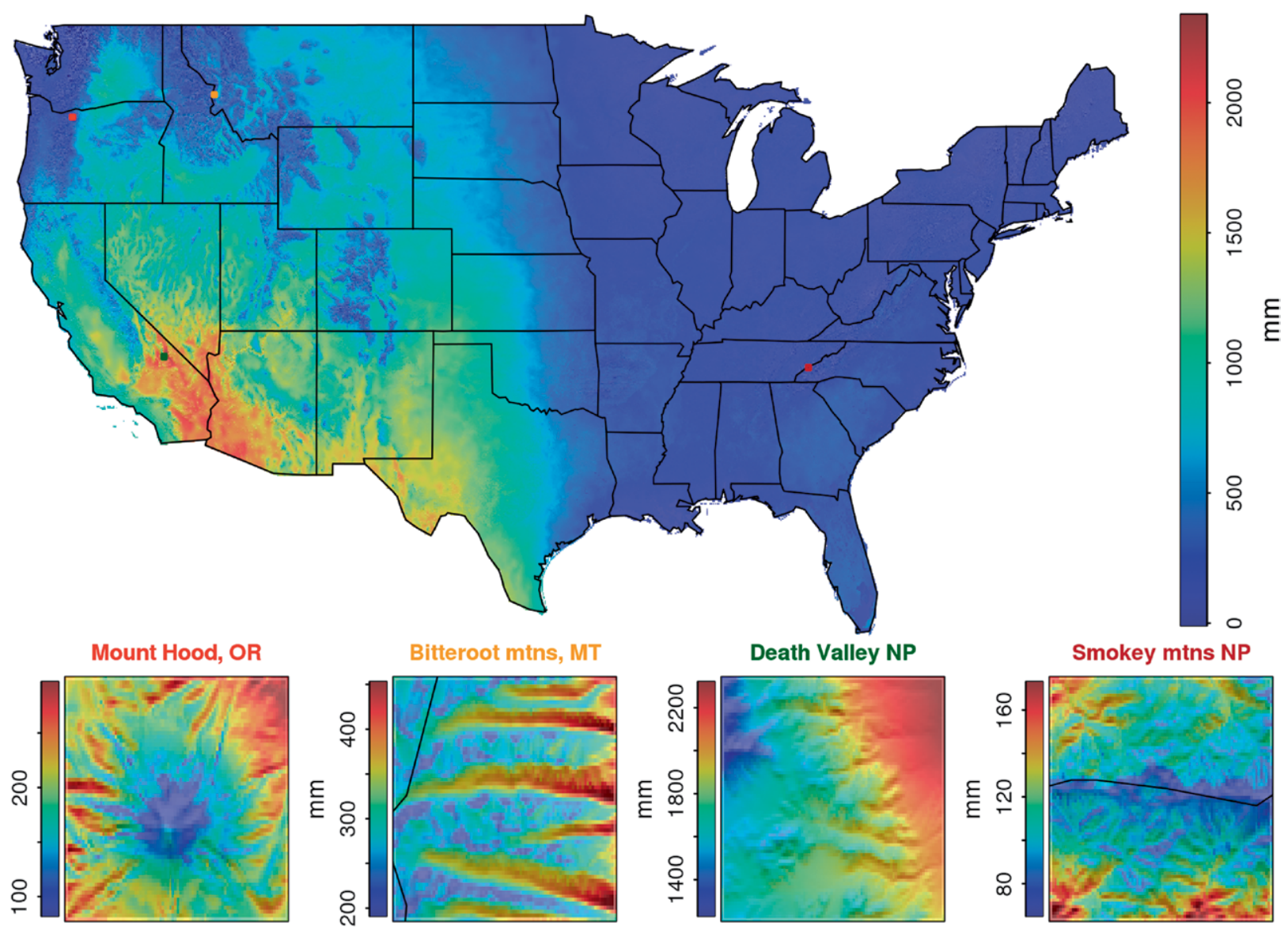

FIG. 4. Thirty-year average (198I-20I0) mean annual climatic water deficit produced from daily historical deficit grids for the conterminous United States. Colored points in the main figure show the location of four inset maps. The insets reveal finescale variations in soil water balance deficits with aspect position, with increased moisture stress on south-facing slopes associated with higher radiation loads and warmer surface air temperatures.

greenness (produced using AVHRR by WFAS) are provided every 8 days using 250 -m resolution MODIS imagery retrieved from the Global Agricultural Monitoring System (GLAM). Two additional drought indices are calculated at 250 - $\mathrm{m}$ resolution using historical 1979-2017 snow and soil water balance datasets produced through this project. Reference or "potential" evapotranspiration (ET) is used to calculate the Evaporative Demand Drought Index (EDDI; Hobbins et al. 2016), a standardized anomaly of potential evapotranspiration. In addition, we calculate a standardized anomaly of climatic water balance deficit - the unmet atmospheric demand for soil moisture. We refer to this index as the cumulative deficit demand index (CDDI) and produce it at a weekly time step for 1-, 4- and 12-week time lags after aggregating daily water balance deficit for the current 7-day period.

High spatial resolution gridded raster datasets may be challenging for drought managers to use in their day-to-day assessments and across large geographic regions because they require significant computational resources for storage and analysis. Each 250-m data layer is approximately 500 megabytes large, and the total volume of the historical gridded datasets is more than 100 terabytes. Furthermore, drought assessments are often made across relatively large areas-for example states, counties, or watersheds. At these broad scales, finescale variations in soil moisture or evaporative demand are difficult to exploit. To facilitate broad level planning and rapid decisionmaking, we summarize drought indices by state and 
county, as well as by Geographic Area Coordination Center (GACC) Predictive Service Area polygons, and provide gridded data extractions as shapefiles with summary statistics for each polygon. In addition to gridded drought products, users can visualize current snowpack conditions at Snow Telemetry stations (SNOTEL) and streamflows at USGS gauges, both of which are updated daily. These data, as well as data from RAWS and cooperative weather stations, are available for download. We provide a video tutorial detailing how to access summary data tools and download and visualize station data on TOPOFIRE.
CONCLUDING REMARKS. As global air temperatures continue to increase and summer dry periods persist or lengthen in the western United States, drought impacts in the coming decades are likely to become more frequent and severe. Informing decisions about how to allocate water and fire management resources and how to manage vegetation will become increasingly important. Fire in many western landscapes is an inevitable and natural process, but their negative effects can be ameliorated with well-informed planning and wildfire response. Making more proactive decisions and facilitating fires burning under less

TABLE I. Gridded datasets produced or displayed on the TOPOFIRE web mapping server. See the article body for acronym definitions.

\begin{tabular}{|c|c|c|c|}
\hline Variable & Description & Source & Resolution/time frame \\
\hline \multicolumn{4}{|c|}{ Soil Moisture / Water Balance } \\
\hline SM & Soil moisture & TOPOFIRE & $240 \mathrm{~m} /$ daily \\
\hline PET & Potential ET & TOPOFIRE & $240 \mathrm{~m} /$ daily \\
\hline AET & Actual ET & TOPOFIRE & $240 \mathrm{~m} /$ daily \\
\hline CWD & Climatic water deficit & TOPOFIRE & $240 \mathrm{~m} /$ daily \\
\hline SWE & Snow water equivalent & TOPOFIRE & $240 \mathrm{~m} /$ daily \\
\hline \multicolumn{4}{|l|}{ Drought Indices } \\
\hline SPEI & Standardized precipitation evaporation index & WWDT & $4,000 \mathrm{~m} / \mathrm{monthly}$ \\
\hline CDDI & Climatic water deficit Anomaly & TOPOFIRE & $240 \mathrm{~m} /$ weekly \\
\hline EDDI & Evaporative demand drought index & TOPOFIRE & $240 \mathrm{~m} /$ weekly \\
\hline VegDRI & Veg. drought response index & USGS & $1,000 \mathrm{~m} / 8$ day \\
\hline $\mathrm{KBDI}$ & Keetch-Byram drought index & TOPOFIRE & $240 \mathrm{~m} /$ daily \\
\hline USDM & U.S. drought monitor & U. Nebraska & NA/weekly \\
\hline \multicolumn{4}{|c|}{ Fuel Moisture and Fire Danger Indices } \\
\hline FMIO & $10 \mathrm{~h}$ fuel moisture & TOPOFIRE & $240 \mathrm{~m} /$ daily \\
\hline FMIO0 & $100 \mathrm{~h}$ fuel moisture & TOPOFIRE & $240 \mathrm{~m} /$ daily \\
\hline FMI000 & $\mathrm{I}, 000 \mathrm{~h}$ fuel moisture & TOPOFIRE & $240 \mathrm{~m} /$ daily \\
\hline ERC & Energy release component & TOPOFIRE & $240 \mathrm{~m} /$ daily \\
\hline $\mathrm{BI}$ & Burning index & TOPOFIRE & $240 \mathrm{~m} /$ daily \\
\hline \multicolumn{4}{|c|}{ Vegetation Indices/Stress } \\
\hline NDVI & NDVI 8 day & MODIS/ GLAM & $250 \mathrm{~m} / 8$ day \\
\hline NDVI Dep. Avg. & NDVI departure from average & MODIS/ GLAM & $250 \mathrm{~m} / 8$ day \\
\hline Rain-free days & Consecutive nonwetting rain days & TOPOFIRE & $2.5 \mathrm{~km} /$ daily \\
\hline
\end{tabular}


extreme conditions will be essential if we want more fire-resilient landscapes in the future. Underlying decisions at the nexus of drought and wildfire management are complex spatial processes that link weather, fuels, and topography. Our hope is that TOPOFIRE data products can one day be integrated with existing fire management tools to foster improved decision making. Similarly, relatively fine-grained, topographically resolved data open opportunities to inform drought mitigation actions at local scales, which is not possible with current drought assessments designed to be applied at state and subcontinental scales.

ACKNOWLEDGMENTS. This work was supported by a grant from the NASA applied sciences program, NNH11ZDA001N-FIRES. We thank Vincent Ambrosia, Amber Soja, and Lawrence Friedl for administrative support. Technical support was provided by the Computational Ecology Laboratory at the University of Montana. We gratefully acknowledge the work of three anonymous reviewers and the editor, whose comments improved the quality and clarity of this manuscript.

\section{FOR FURTHER READING}

Abatzoglou, J. T., D. J. McEvoy, and K. T. Redmond, 2017: The West Wide Drought Tracker: Drought monitoring at fine spatial scales. Bull. Amer. Meteor. Soc., 98, 1815-1820, https://doi.org/10.1175/BAMS -D-16-0193.1.

Brown, J. F., B. D. Wardlow, T. Tadesse, M. J. Hayes, and B. C. Reed, 2008: The Vegetation Drought Response Index (VegDRI): A new integrated approach for monitoring drought stress in vegetation. GIsci. Remote Sens., 45, 16-46, https://doi.org/10.2747/1548 -1603.45.1.16.

Burgan, R. E., P. L. Andrews, L. S. Bradshaw, C. H. Chase, R. A. Hartford, and D. J. Latham, 1997: WFAS:
Wildland fire assessment system. Fire Manag. Notes, 57, 14-17.

Finney, M., 1998: FARSITE: Fire Area Simulator-model development and evaluation. USDA Forest Service Rocky Mountain Research Station Tech. Rep. RP-4, $47 \mathrm{pp}$.

Geiger, R., R. H. Aron, and P. Todhunter, 1995: The Climate Near the Ground. Springer Nature, 528 pp.

Hobbins, M. T., A. Wood, D. J. McEvoy, J. L. Huntington, C. Morton, M. Anderson, and C. Hain, 2016: The Evaporative Demand Drought Index. Part I: Linking drought evolution to variations in evaporative demand. J. Hydrometeor., 17, 1745-1761, https://doi .org/10.1175/JHM-D-15-0121.1.

Holden, Z. A., and W. M. Jolly, 2011: Modeling topographic influences on fuel moisture and fire danger in complex terrain to improve wildland fire management decision support. For. Ecol. Manage., 262, 21332141, https://doi.org/10.1016/j.foreco.2011.08.002.

— , and Coauthors, 2016: Development of high-resolution $(250 \mathrm{~m})$ historical daily gridded air temperature data using reanalysis and distributed sensor networks for the US Northern Rocky Mountains. Int. J. Climatol., 36, 3620-3632, https://doi.org/10.1002/joc.4580. — , and Coauthors, 2018: Decreasing fire season precipitation increased recent western US forest wildfire activity. Proc. Natl. Acad. Sci. USA, 115, https://doi .org/10.1073/pnas.1720804115.

Svoboda, M., and Coauthors, 2002: The Drought Monitor. Bull. Amer. Meteor. Soc., 83, 1181-1190, https:// doi.org/10.1175/1520-0477-83.8.1181.

Vicente-Serrano, S. M., S. Beguería, and J. I. LópezMoreno, 2010: A multiscalar drought index sensitive to global warming: The standardized precipitation evapotranspiration index. J. Climate, 23, 1696-1718, https://doi.org/10.1175/2009JCLI2909.1.

Whiteman, D. C., 2000: Mountain Meteorology: Fundamentals and Applications. Oxford University Press. 355 pp. 